\title{
Football Misinformation Matrix: A Comparative Study of 2020 Winter Transfer News in Four European Sports Media Outlets
}

\author{
José Luis Rojas Torrijos ${ }^{1, *(1)}$ and Matheus Simoes Mello ${ }^{2}$ \\ 1 Departamento de Periodismo II, Facultad de Comunicación, Universidad de Sevilla, 41092 Sevilla, Spain \\ 2 Department of Journalism, Campus Centro, Lutheran Institute of Santa Catarina, Joinville 89201-270, Brazil; \\ matheus.mello@ielusc.br \\ * Correspondence: jlrojas@us.es
}

check for

updates

Citation: Rojas Torrijos, José Luis, and Matheus Simoes Mello. 2021. Football Misinformation Matrix: A Comparative Study of 2020 Winter Transfer News in Four European Sports Media Outlets. Journalism and Media 2: 625-640. https://doi.org/ 10.3390/journalmedia2040037

Academic Editor: Andreu Casero-Ripollés

Received: 14 September 2021

Accepted: 14 October 2021

Published: 20 October 2021

Publisher's Note: MDPI stays neutral with regard to jurisdictional claims in published maps and institutional affiliations.

Copyright: (c) 2021 by the authors. Licensee MDPI, Basel, Switzerland. This article is an open access article distributed under the terms and conditions of the Creative Commons Attribution (CC BY) license (https:/ / creativecommons.org/licenses/by/ $4.0 /)$.

\begin{abstract}
Mainstream sports media generate a football information overload that sometimes makes it difficult to separate rumours from real news. Accordingly, this paper analyses the level of misinformation in the coverage of the 2020 winter football transfer window in four leading European digital sports media outlets: Marca (Spain), A Bola (Portugal), La Gazzetta (Italy) and The Guardian Sport (Britain). The methodology used was based on the content analysis of hundreds of news pieces and tweets posted on these outlets' football homepages and Twitter handles over a month. To examine to what extent this coverage may have been speculative, misleading or false, the misinformation matrix developed by the fact-checking organisation First Draft News was employed to classify five different types of inaccuracies in sports reporting. A system was also created to determine how many reported rumours finally turned out to be true, which sources were more reliable and what outlets resulted more accurate. The findings reveal that the four digital media published a larger amount of non-factual content about likely football deals rather than sealed transfers. Speculative reporting prevailed in the coverage of the top teams in each league, on which the media outlets placed the accent, whereas reporting about minor clubs was based more on factual news.
\end{abstract}

Keywords: sports journalism; football; transfer window; misinformation; rumours; ethics

\section{Introduction}

Mainstream sports journalism still sets a daily news agenda lacking in diversity. Media outlets in this field tend to overlook some disciplines and competitions in their daily coverage, in which women's sports and female athletes scarcely gain a small fraction of sports media attention. What is covered and what is not turn out to be a consequence of a sports newswork model that perpetuates "a male-dominated, hegemonic nature of sports newsrooms, settled and ingrained assumptions about readership, and the systematic, repetitive nature of sports news" (Sherwood et al. 2017, p. 647).

As a result of the particular conditions of this "beat model" where reporters are assigned to cover a particular sport or team, the sports media coverage worldwide is basically male-oriented and in most countries focuses on a few professional football clubs and players. More often than not, the "footballisation" of sports journalism (Rojas-Torrijos 2012) involves a football information overload that makes it increasingly difficult to separate the noise from real news. This is particularly the case of information about transfer windows, which open twice a year in the major European leagues.

Despite the fact that telling the truth is "journalism's first obligation" (Kovach and Rosenstiel 2007, p. 12) and major ethical codes and media accountability instruments in this respect make explicit reference to avoiding conjectures (Plaisance 2013; Ramon and Rojas-Torrijos 2017), speculative reporting has become "a central aspect of contemporary sports journalism" (Boyle 2006, p. 93).

In football, "a sport known for its post-truth propagation of transfer rumours" (Smith 2017), news outlets sometimes cover unverified claims, online gossip and viral content, 
thus contributing to spreading lies (Silverman 2015) across all digital platforms. In the social media age, false content spreads "significantly farther, faster, deeper, and more broadly than the truth in all categories of information" (Vosoughi et al. 2018, p. 1146).

Although false content has always existed in journalism, several aspects of the digital media environment have made it easier for misinformation to reach more people and become global. Firstly, the increasingly stiffer competition between media outlets in the new "marketplace of attention" (Webster 2014) has led them to compete in a race in which they finally tend to rely more on self-interested sources than on original reporting (Thorson 2016, p. 476).

On the other hand, on social media platforms, sports media outlets have less control over distribution and gatekeeping processes, thus making it easier for readers to obtain false or fabricated information, although they may have a hard time distinguishing it from real news (Nielsen and Graves 2017). All these changes have raised questions about the viability of media to produce reliable information and about the social role and authority of journalism (Ekström and Lewis 2020, p. 206).

The pressure on media to compete and conquer fragmented audiences as well as the pre-eminent role of social networks to set the pace in the current newsroom workflows are both determined by the digital $24 \mathrm{hr}$ news cycle. This requires the media outlets need to produce news at extreme speed that may well end up being a "menace" by giving rise to more opinion and wild speculation as news (Rosenberg and Feldman 2008).

The accelerated nature of online news has also favoured the position of Twitter as the most utilized social media platform by sports journalists. According to English (2016), the heavy use of this social media site has caused changes to traditional news gathering and publishing techniques in sports coverage to the extent that is occasioning a "paradigm shift" in the field (Schultz and Sheffer 2010). This shift implies that sports media try constantly to break news, or rare scoops (Moritz and Mirer 2021), on Twitter as soon as they are confirmed before expanding the story in any other platform.

Nevertheless, this trend has also stimulated the growth of 'clickbait culture', in which reporters and editors produce sensationally headlined stories with the aim of attracting a higher number of visitors to websites (Bradshaw 2021, p. 20). However, as Cable and Mottershead (2018) explain, the pursuit of audience through clickbait techniques has undermined the quality of sports coverage. These authors consider this strategy of producing more clickbait content may be a short-sighted way of trying to build a loyal community of users.

Instead, clickbait reinforces the production of content that sports journalists and sports media outlets "believe their audiences prefer and will generate traffic to social media accounts and websites" (Domeneghetti 2021, p. 179) and income via advertising. In the wake of this, complex stories are left behind in favour of those ones than can be easily written and consumed. In sports journalism, breaking news, which "often revolves around transfer stories" (Moritz and Mirer 2021, p. 139), are among those quick online stories that provide metrics to media organisations.

In this context, the winter and summer football transfer windows are the perfect time for starting and spreading rumours, especially when there is no World Cup or any other international tournament in the offing. Consequently, both likely and confirmed player signings occupy a central position in the agenda-setting of sports media outlets (Chadwick 2013).

In a similar way to other journalistic areas, misinformation in football news coverage becomes "a problem driven by a combination of some news media who publish it, some sources who contribute to it, and some platforms that help distribute it" (Nielsen and Graves 2017, p. 1). Normally, published rumours about transfers are "stories designed to take root in an explicitly partisan environment", where fans want to believe them regardless their veracity (Smith 2017).

To put it bluntly, rumours about new signings are commonly seen as an opportunity for fans, media and non-neutral sources who may perceive benefits in starting and spreading 
them. As Chadwick (2013) explains, for fans, rumours about new signings encourage them to buy tickets and to consume news; for media, they serve to drive traffic to their platforms when there is otherwise not much else to report on, and for partisan sources (agents), they are sometimes "used for market-signalling purposes".

Nonetheless, the spread of misinformation in sports journalism is still an underexplored issue in the academic literature. For this reason, it is necessary to define the way in which hearsay marks and permeates sports journalists' newsgathering and reporting practices in the current media landscape. This approach also begs the "increasingly critical" question of how and when misinformation, as the opposite of news and truth (Waisbord 2018), shapes audience attitudes (Thorson 2016, p. 476) and to what extent the misleading or false content that these media outlets disseminate may affect their credibility (Hayes et al. 2007).

\section{Research Design}

This research analyses the level of misinformation in European sports media coverage of the 2020 winter football transfer window. To this end, a comparative study was performed to examine the way in which football reporting may or may not comply with ethical standards, such as the verification of and distinction between rumours and facts and, consequently, the extent to which news about the transfer market may be speculative, misleading or even false.

The term "misinformation" is used here rather than "disinformation" (Ireton and Posetti 2018) or the widely used "fake news" (Allen et al. 2020; Tsfati et al. 2020). News is supposed to include accurate and real information, whereby it should be based on the truth, "which makes the term 'fake news' an oxymoron" (Tandoc et al. 2018, p. 140). Following Wardle (2019, p. 8), "disinformation" refers to the intentional dissemination of information known to be false, but which becomes "misinformation" when shared and disseminated across all platforms. Misinformation also describes false or misleading content which, nonetheless, individuals believe to be true.

\subsection{Research Objectives and Questions}

In light of the foregoing, the research objectives were as follows:

- To detect rumours and false content in the sports media coverage of winter football transfers/loans in four top European leagues in 2020;

- To identify and distinguish between different types of factual inaccuracies in sports reporting about the 2020 winter transfer window;

- To gauge the extent to which the reported rumours ultimately proved to be true;

- To analyse and compare the sources employed by media outlets so as to evaluate the levels of reliability and accuracy that can be expected from sports reporting about football transfers/loans.

In order to meet the research objectives, the following four research questions (RQ) were formulated:

- (RQ1): How much misinformation did major European sports media outlets spread in their coverage of the 2020 winter football transfer window?

- (RQ2): What kind of factual inaccuracies did these sports media outlets include in their reporting?

- (RQ3): What proportion of rumours published by these sports media outlets actually turned out to be true?

- (RQ4): Which of these sports media outlets were more accurate in their coverage and, therefore, may be considered as being more reliable, according to the sources that they used?

\subsection{Method}

So as to conduct this comparative research, a content analysis was performed on Twitter posts and news pieces posted on the websites of four leading European sports 
media outlets: Marca (Spain), A Bola (Portugal), La Gazzetta dello Sport (Italy) and The Guardian's "Guardian Sport" (Britain).

Content analysis is a research technique "for making replicable and valid inferences from texts to the contexts of their use" (Krippendorf 2019, p. 24). As an empirically grounded method, it enables researchers to read, interpret and make valid inferences about the manifest content of Twitter posts in a systematic way. With the aim of answering the abovementioned research questions (RQ1-RQ4), this method was applied to the tweets that the four sports media outlets posted on their accounts and to the news that they published on their football homepages.

Marca, A Bola, La Gazzetta dello Sport and The Guardian's "Guardian Sport" section have some aspects in common. This is due to the specific sporting culture prevailing in Spain, Portugal, Italy and the United Kingdom in which football is indisputably the king (Murray 1998; Reilly and Williams 2003) and to their particular media systems characterised by the relevance and tradition of a national sports press. In other words, they not only represent four of the oldest sports journalism schools on the continent (Torrebadella and Olivera 2013), but also cover in depth four of the major professional football leagues in the world.

La Gazzetta, established in 1896, is the oldest sports daily in Europe and the leading newspaper in Italy (Brunner and Horky 2017), whereas Marca is currently the most widely read sports tabloid in Spain (AIMC 2021) and even in other Spanish-speaking countries (Rojas-Torrijos 2018). Similarly, A Bola stands out as the major Portuguese sports daily with a circulation not only in Portugal but also in international editions in France and in Portuguese-speaking African countries (Angola and Mozambique). For its part, The Guardian's award winning "Guardian Sport" has become one of the most outstanding sports sections in Britain, where there are no sports dailies except for The Racing Post, while other "quality dailies" fill that gap with extensive daily sports sections (Crolley and Hand 2002, p. 3).

The official Twitter accounts and the football homepages of the four sports media outlets are as follows: @marca, @gazzetta_it, @abolapt and @guardian_sport, on the one hand, and www.marca.com/futbol.html (accessed on 20 July 2021), www.abola.pt (accessed on 20 July 2021), wwww.gazzetta.it/Calcio/ (accessed on 20 July 2021) and www.theguardian.com/football (accessed on 20 July 2021), on the other. All four of them are very popular, as evidenced by the number of followers on their Twitter accounts, according to data collected on 31 March 2020: @marca (5.4 million), @gazzetta_it (1.7 million), @guardian_sport $(853,400)$ and @abolapt $(145,600)$.

The research corpus was made up of a sample of tweets and news pieces and/or rumours posted on the Internet. A rumour is understood here as an unverified piece of information (Kapferer 2013), which has neither been officially confirmed, nor is it based on a news outlet's own investigative efforts (but on what other media outlets have published or on a sole source) or properly attributed (unknown source). To ensure the rigour of the study and the comparability between the Twitter accounts and the football homepages of the four sports media outlets, observations were carried out between 1-31 January 2020, coinciding with the one-month period during which the winter football transfer window remains open every year.

To ensure the retrieval of all the content on football transfers/loans published by the four media outlets during the study time frame, data collection was performed on a daily basis. The stream of tweets displayed on each timeline and their links to the web were comprehensively examined once a day, every morning, whereas the football homepages were reviewed twice a day (at 10:00 a.m. and 10:00 p.m.) in order to identify the position that the news pieces/rumours which had already been posted on Twitter had occupied on the Web throughout the day.

For the specific purpose of evaluating how the four sports media outlets prioritised their online coverage of football transfers/loans, only the first 10 news pieces appearing on their football homepages were considered as being of "prime concern". 
Once the tweets $(n=177)$ and the online news pieces $(n=211)$ had been retrieved, they were processed with Microsoft Excel and examined using the content analysis technique.

To answer RQ1, all the published units of content about football transfers were taken into consideration as long as they fulfilled the following nine criteria:

1. The unit of content had to be presented as a news piece, with comments and in-depth analyses being discarded.

2. News based on statements made by any player (or coach) expressing his ideas or feelings about his own transfer were also excluded. As they are non-factual, news pieces of this type do not help to distinguish between news based on confirmed transfers/loans and unverified information.

3. Moreover, football news pieces that neither reported nor suggested any (possible) transfer/loan were discarded.

4. Videos or any other non-textual content were also dispensed with.

5. News pieces had to refer to one (possible) transfer/loan or to just one club. Summaries of short news and flashes, liveblogging posts and long pieces containing window transfer updates were not considered. Pieces of this kind do not allow for a proper analysis of the key elements of each unit of content, such as the choice of headline, the way in which the text was written or how the information was obtained (sources).

6. Several tweets about an individual deal between a player/club were counted as just one.

7. The sample only comprised news (or rumours) regarding transfers/loans occurring during the 2020 winter transfer window and taking effect in the 2019-2020 season. The transfers signed in January 2020 for the following season were not included in the sample.

8. The sample only included reports on footballers' (and coaches') transfers/loans from/to teams playing in the four national leagues included in this study: Portugal, Spain, Italy and England. In other words, transfers/loans concerning other European and non-European championships were disregarded.

9. The transfers/loans included in the research sample only took place between first division teams in each league. This information could refer to a deal between two clubs in the same league or in different leagues.

Following the sample selection process, a content analysis was performed. To this end, a worksheet with the following six items was created for examining each unit of content in the sample:

1. League;

2. Team or club;

3. Player (or coach) transferred/loaned;

4. Whether or not the sports media outlet cautioned readers that what was involved was a rumour (section in which the news piece appeared);

5. Sources mentioned in the text: first-hand news, second-hand information (sources) or no sources;

6. Headline: whether or not the source was mentioned. When the source was not mentioned:

a. the conditional or;

b. ambiguous expressions ("It would seem that ...", "They say that he will be playing for ... ", "In (name of the country), it has been remarked that ...", etc.) were employed.

As a result of this content analysis, the texts in the sample were divided into two main groups:

- Factual news or rumours (about a transfer/loan that went through);

- Non-factual content (the transfer is reported to be true but did not happen yet or never). 
To answer RQ2, recourse was had to the misinformation matrix, developed by the factchecking organisation First Draft News (Wardle 2019) as a tool for classifying the different types of factual errors that may be found in sports reporting. This tool was adapted to the research objectives by merging the seven original categories into five types of imprecisions: fabricated or manipulated content, imposter content, content reframed with a false context and misleading content, false connection and satire or parody.

According to this misinformation matrix, factual errors are classified as follows:

1. Fabricated or manipulated content (two original categories were merged into one to respond to the reality of sports reporting and sources). News content that is essentially or mostly false, designed to deceive or mislead public opinion (sometimes by putting a player's name in the news to increase his market value). This mainly comes from unofficial or partisan sources, such as leaks from players' agents.

2. Imposter and hidden content. Genuine sources are impersonated, hidden or mistaken (identity). In this case, sources are not cited in the information, either because some refuse to share information without the shield of anonymity or because the journalist involved may have neglected to verify the information (ethical failure). Unlike fabricated content, in this case, stories are not completely false but may become distorting for readers because they cannot infer where the facts really stem from or when some parts of the story have been omitted.

3. Content reframed with a false context and misleading content (two original categories were merged into one to respond to the reality of sports reporting and sources). Mostly or absolutely genuine content is disseminated with false or contextual information, consequently misleading audiences. This usually happens when the journalist does not devote enough time to newsgathering or when reporting is biased.

4. False connection. Headlines, photographs and captions do not support the content. This usually corresponds to sensationalist practices, such as clickbaiting, or to search engine optimisation (SEO) strategies for selecting tags/keywords to drive more traffic from search engines like Google.

5. Satire or parody. News pieces have entertainment (humorous, anecdotal, etc.) rather than informational purposes. Nevertheless, they have the potential to confuse or deceive public opinion. Notwithstanding the fact that these stories are published in the knowledge that they are false, the public reading them on any digital platform may give them some credibility. These news pieces are usually poorly written or filler content deriving from the monitoring of sportspeople's social media photos and posts.

Following the analysis, the fifth category was finally discarded because not one satirical or humorous story was detected in the sample.

Finally, to answer RQ3 and RQ4, a system was created to determine how many of the factual news pieces and rumours finally became a reality, which sources were more trustworthy and which of the four sports media outlets were more accurate and reliable.

To this end, all the news pieces in the sample were divided into two categories: those reporting deals that went through (thus considered as accurate stories) and those reporting deals that did not. The sum of all the accurate stories was then divided by the total of reported deals to determine the level of accuracy of each sports media outlet. Based on whether or not the reported deal actually went through, the resulting scores may be regarded as being valid for the specific research objectives of this study. All of which then allowed for determining the following:

- The total number of transfers/loans reported by the four sports media outlets in this study;

- The teams or counties in which the transferred/loaned footballers (or coaches) played (despite extensive global scouting networks, league-to-league transfers/loans are usually given far more coverage in national media outlets than deals between clubs in different leagues); 
- The total number of reported deals that finally went through and the level of accuracy of each media outlet (which media outlets were more reliable?);

- The level of accuracy or inaccuracy of reported deals depending on the clubs (were rumours about certain clubs more accurate?);

- The most reported deals that were subsequently brought off (the most talked about players/coaches);

- The most reported deals that did not go through (the most talked about players/coaches).

In light of these findings, it was possible to gauge how much misinformation exists in sports reporting about European football transfers/loans and to what extent this varies depending on the main actors (footballers/coaches and clubs) and the sources employed by sports media outlets.

\section{Results}

The month-long analysis of the sample of 177 tweets and 211 news pieces relating to football transfers/loans shows that the four media news outlets consistently covered developments during the 2020 winter transfer window both on their Twitter accounts and their football homepages. During the time frame of observation, however, there were quantitative and qualitative differences in their coverage in this respect.

\subsection{Misinformation (RQ1)}

Regarding the proportion between factual information and rumours appearing on their Twitter accounts and football homepages, the results confirm that the four sports media outlets tended to post a larger number of tweets and news pieces about unconfirmed football transfers/loans than about sealed deals.

Firstly, as shown below in Table 1, the tweets posted by all the sports media outlets, except for Marca, contained more rumours ( $n=113 ; 63.85 \%)$ than factual news ( $n=64$; $36.15 \%)$, with A Bola $(n=24 ; 77.4 \%)$ and La Gazzetta $(n=43 ; 75.5 \%)$ way out in the front as regards misinformation.

Table 1. The table shows the distribution among the four news outlets of pieces of news and rumours published during the 2020 winter football transfer window.

\begin{tabular}{lcccc}
\hline On Twitter & & & & \\
\hline Media Outlet & Total & News & Rumours & \% \\
\hline Marca & 56 & 28 & 28 & $50-50$ \\
Guardian Sport & 33 & 15 & 18 & $45.5-54.5$ \\
A Bola & 31 & 7 & 24 & $22.6-77.4$ \\
La Gazzetta & 57 & 14 & 43 & $24.5-75.5$ \\
\hline Total & $\mathbf{1 7 7}$ & $\mathbf{6 4}$ & $\mathbf{1 1 3}$ & $\mathbf{3 6 . 1 5 - 6 3 . 8 5}$ \\
\hline On Websites & & & & \\
\hline Marca & 78 & 48 & 30 & $61.5-38.5$ \\
Guardian Sport & 43 & 20 & 23 & $46.5-53.5$ \\
A Bola & 53 & 83 & 30 & $43.4-56.6$ \\
La Gazzetta & 37 & $\mathbf{9 9}$ & $\mathbf{2 9}$ & $\mathbf{2 1 . 6}-78.4$ \\
\hline Total & $\mathbf{2 1 1}$ & & $\mathbf{1 1 2}$ & $\mathbf{4 6 . 9 - 5 3 . 1}$ \\
\hline
\end{tabular}

By contrast, rumours were less prevalent in the news pieces $(n=112 ; 46.9 \%)$ appearing on the football homepages of the four sports media outlets, thus suggesting that they offered more coverage of officially confirmed transfers/loans here than on their Twitter accounts.

This consistent combination of factual news and gossip in football transfer/loan coverage may have led to confusion among audiences. This was not the case of the football homepage of The Guardian, which let readers know when reports were rumours by including a link to its "Transfer Interactive" or "Rumour Mill" section. These two sections act as radars providing market updates and breaking news about transfers/loans. 
The former includes every deal in Europe's top five leagues (Premier, la Liga, Serie A, Bundesliga and Ligue 1 in France), while the latter mostly includes gossip and unconfirmed news about English teams and players. Although actual transfers/loans were clearly distinguished from rumoured ones on the football homepage of The Guardian, they were still mixed, meaning that this outlet published more rumours on its football homepage than on its sports Twitter handle.

Despite the fact that the line between factual and non-factual information was blurred in most of the football news pieces in the sample, some rumours could be easily identified in two situations: firstly, when the headline ended in a question mark and, secondly, when the main verb in the sentence was in the conditional. The first trend was more evident in The Guardian Sport's Rumour Mill section, whereas the second one was more common in Marca and A Bola.

\subsection{Factual Errors (RQ2)}

With regard to rumours about the 2020 winter transfer window, different types of factual errors were observed in the coverage of all the sports media outlets. The majority of evident hearsay was based on hidden content in the reporting, while, more often than not, there was a higher quantity of unconfirmed news including content reframed with a false context, which turned out to be misleading, on both the Twitter handles and football homepages of the four sports media outlets, as summarized in Table 2.

Table 2. The table shows the types of factual errors shown by the four sports media outlets in their coverage.

\begin{tabular}{lccccc}
\hline On Twitter & Marca & Guardian & A Bola & Gazzetta & $\boldsymbol{n} \mathbf{\%}$ \\
\hline Category & 6 & 3 & 4 & 6 & $19 / 16.8$ \\
\hline Fabricated content & 11 & 11 & 5 & 15 & $42 / 37.2$ \\
Imposter/hidden content & 5 & 4 & 9 & 17 & $35 / 31$ \\
False context/misleading c. & 6 & 0 & 6 & 5 & $17 / 1521.6-78.4$ \\
False connection & & & & & $\mathbf{1 0 0}$ \\
\hline Total $(\boldsymbol{n}=\mathbf{1 1 3})$ & & & & & \\
\hline On Websites & 7 & 3 & 9 & 7 & $26 / 23.2$ \\
\hline Fabricated content & 12 & 14 & 9 & 10 & $45 / 40.2$ \\
Imposter/hidden content & 5 & 6 & 7 & 11 & $29 / 25.9$ \\
False context/misleading c. & 6 & 0 & 5 & 1 & $12 / 10.7$ \\
False connection & & & & & $\mathbf{1 0 0}$ \\
\hline Total $(\boldsymbol{n}=\mathbf{1 1 2})$ & &
\end{tabular}

There were also factual errors in fabricated or manipulated content, mainly coming from unofficial or partisan sources such as football agents. Moreover, all the news outlets, except for The Guardian, published news pieces with content reframed with a false context, normally in follow-up pieces on negotiations between clubs that were supposed to be close to completion and which were considered to be highly newsworthy. This was the case of $A$ Bola's misleading coverage of the negotiations between Benfica and the Brazilian midfielder Bruno Guimarães, who finally signed for Lyon.

\subsection{Levels of Accuracy and Reliability (RQ3 and RQ4)}

Although the four sports media outlets included different types of factual errors in their coverage, some of those deals that were initially reported as being rumours finally went through and were confirmed during the 2020 winter transfer window, as shown in Table 3. 
Table 3. The table shows the percentage of published rumours about football deals that finally happened.

\begin{tabular}{|c|c|c|c|c|}
\hline On Twitter & & & & \\
\hline Media Outlet & Total of Rumours & Happened & Did Not & $\%$ \\
\hline Marca & 28 & 14 & 14 & 50 \\
\hline Guardian Sport & 18 & 9 & 9 & 50 \\
\hline A Bola & 24 & 9 & 15 & 37.5 \\
\hline La Gazzetta & 43 & 19 & 24 & 44.2 \\
\hline Total & 113 & 51 & 62 & 45.1 \\
\hline \multicolumn{5}{|l|}{ On Websites } \\
\hline Marca & 30 & 14 & 16 & 46.3 \\
\hline Guardian Sport & 23 & 7 & 16 & 30.4 \\
\hline A Bola & 30 & 9 & 21 & 30 \\
\hline La Gazzetta & 29 & 16 & 13 & 55.2 \\
\hline Total & 112 & 46 & 66 & 41 \\
\hline
\end{tabular}

In spite of the confusion to which reporting hearsay as fact usually gives rise, the four sports media outlets had no qualms about publishing a number of tipoffs, speculations and statements coming from anonymous sources, which, in the course of events, would turn out to be true when the deals or signings were ultimately announced or confirmed by official sources (clubs).

La Gazzetta stood out as being the most reliable in this respect on both platforms ( $n=43,44.2 \%$ on Twitter; and $n=29,55.2 \%$ on its football homepage), followed by Marca ( $n=28,50 \% ; n=30,50 \%)$. At the other end of the scale, A Bola proved to be the least reliable $(n=24,37.5 \% ; n=30,30 \%)$.

In the research sample the four media outlets sometimes described deals as if they were already sealed. However, in some cases, they would finally occur a few hours/days later, such as Andraz Sporar's transfer to Sporting (Portugal), whereas others never happened. This means that outlets delivered information (about transfer fees, salaries or contract duration) considering that contract was already signed, but it was not actually. In most of these misleading pieces, it is interesting to observe that sources were rarely mentioned.

La Gazzetta dello Sport, for example, published on its website that Uruguayan left-back Matías Viña had decided to move to AC Milan. The Italian newspaper reported that the player was going to meet Nacional's (his team) president to communicate his decision and provided detailed information about when (next day) and who (his mother) was going to take part in the meeting. This piece finally concluded that, despite the player had received another offer from Palmeiras (Brazil), he had already chosen Milan. Nevertheless, Palmeiras would announce the signing of Viña a few hours later.

The high proportion of reported rumours that were finally confirmed may have actually increased the level of accuracy and/or reliability of the reporting of the four sports media outlets. Consequently, to gauge the level of accuracy of the coverage of each one of them, all the deals that they reported that finally went through, namely, the number of factual news pieces about sealed deals, plus the number of rumours that proved to be correct, were aggregated (see Table 4).

The scores obtained by the sports media outlets varied greatly. Marca led the ranking on both platforms ( $n=42,75 \%$, on Twitter, and $n=62,79.5 \%$, on its football homepage), followed closely by the Twitter account of The Guardian's "Guardian sport" section ( $n=24$, $73.2 \%)$ and the football homepage of $L a$ Gazzetta $(n=24,76.8 \%)$. Whereas The Guardian's section posted more factual news on Twitter, La Gazzetta achieved the highest score in rumours that were ultimately confirmed on both platforms. A Bola yet again brought up the rear $(n=16,51.6 \%$, on Twitter, and $n=32,60.4 \%$, on its football homepage). Furthermore, the average level of accuracy of the information appearing on the football homepages of the four sports media outlets was $69.8 \%$ per cent, almost three points higher than on their Twitter accounts $(67 \%)$. 
Table 4. The table shows the scores of accuracy obtained by each sports media outlet.

\begin{tabular}{|c|c|c|c|}
\hline \multicolumn{4}{|l|}{ On Twitter } \\
\hline Media Outlet & News $\%$ & Rumours That Happened \% & Score $\%$ \\
\hline Marca & 50 & 25 & 75 \\
\hline Guardian Sport & 45.5 & 27.7 & 73.2 \\
\hline A Bola & 22.6 & 29 & 51.6 \\
\hline La Gazzetta & 24.5 & 44.2 & 68.7 \\
\hline Average & 35.6 & 31.4 & 67 \\
\hline \multicolumn{4}{|l|}{ On Websites } \\
\hline Marca & 61.5 & 18 & 79.5 \\
\hline Guardian Sport & 46.5 & 16.3 & 62.8 \\
\hline A Bola & 43.4 & 17 & 60.4 \\
\hline La Gazzetta & 21.6 & 55.2 & 76.8 \\
\hline Average & 43.2 & 26.6 & 69.8 \\
\hline
\end{tabular}

It should also be noted that the proportion of rumours in the sports media outlets' coverage of the 2020 winter football transfer window differed depending on the relevance of the clubs and players involved. So, sometimes, the greater the amount of content that was devoted to the top clubs and the most popular players in a national league, the greater the chances of gathering rumours and publishing speculative pieces and non-factual articles based on them would be.

The research results clearly confirm this likelihood. For instance, $M a r c a$ 's coverage of the 2020 winter football transfer window contained more gossip when this involved Real Madrid, F.C. Barcelona and Atlético de Madrid. In contrast, its coverage of the rest of football clubs in La Liga was more factual.

As shown in Table 5, this was also the case with A Bola and La Gazzetta. Whereas the Portuguese sports media outlet's coverage of minor clubs, which was normally based on official announcements, was spot on, that of the three major teams in the Primeira Liga (Benfica, FC Porto and Sporting) was more inaccurate, with detailed accounts of negotiations and likely transfers/loans. As for La Gazzetta, four top clubs (Juventus, Milan, Inter and Napoli) were considered apart because they dominated its football coverage and accounted for most of the rumours. In this case, however, the level of accuracy of its coverage of other Serie A teams was not high either: Only one out of three of its news pieces was about closed deals.

The level of accuracy of The Guardian's "Guardian Sport" section when covering deals involving major clubs was higher than the rest of the sports media outlets on Twitter $(n=15,33.3 \%)$ and came second only to Marca $(n=19,26.3 \%)$ on its football homepage $(n=19,21 \%)$. Despite this high score, the British newspaper also published more rumours about top teams than about minor clubs, which mostly appeared in brief pieces and were referred to as sealed transfers.

In this study, the three most relevant teams for The Guardian were Manchester United, Chelsea and Tottenham. These clubs have been considered as the Top 3 despite they are not necessarily the most popular ones. During the 2020 winter transfer window, Manchester City and Liverpool, the two leading teams at the end of the previous Premier League season, did not buy any player.

In contrast to the Italian, Spanish and Portuguese first division leagues, where there is a clear difference between the Top 3 and the rest of sides, the English Premier League title may be disputed by five or six teams every season. The increasing number of clubs owned by multimillionaire businessmen who invest in the game could add or remove teams from that list within the next years. In this case, Manchester United, Chelsea and Tottenham were the ones that received more media attention during the 2020 winter transfer window. 
Table 5. The table shows the amount of factual reporting regarding the clubs involved in the published pieces of news and rumours.

\begin{tabular}{|c|c|c|c|c|}
\hline \multicolumn{5}{|l|}{ On Twitter } \\
\hline Media Outlet & Clubs & Total & News Rumours & $\%$ \\
\hline \multicolumn{5}{|l|}{ Marca } \\
\hline Real Madrid, Barça, At. Madrid & 19 & 5 & 14 & 26.3 \\
\hline Other teams from La Liga & 37 & 23 & 14 & 62.1 \\
\hline \multicolumn{5}{|l|}{ Guardian Sport } \\
\hline Man Utd., Chelsea, Tottenham & 15 & 5 & 10 & 33.3 \\
\hline Other Premier League teams & 18 & 10 & 8 & 55.5 \\
\hline \multicolumn{5}{|l|}{ A Bola } \\
\hline Benfica, FC Porto, Sporting & 26 & 3 & 23 & 11.5 \\
\hline Other teams from Primeira Liga & 5 & 5 & 0 & 100 \\
\hline \multicolumn{5}{|l|}{ La Gazzetta } \\
\hline Juventus, Inter, Milan, Napoli & 39 & 7 & 32 & 18 \\
\hline Other Serie A teams & 18 & 7 & 11 & 39 \\
\hline \multicolumn{5}{|l|}{ On Websites } \\
\hline \multicolumn{5}{|l|}{ Marca } \\
\hline Real Madrid/Barça/At. Madrid & 19 & 5 & 14 & 26.3 \\
\hline Other teams from La Liga & 59 & 35 & 16 & 59.3 \\
\hline \multicolumn{5}{|l|}{ Guardian Sport } \\
\hline Man Utd., Chelsea, Tottenham & 19 & 4 & 15 & 21 \\
\hline Other Premier League teams & 24 & 16 & 8 & 66.6 \\
\hline \multicolumn{5}{|l|}{ A Bola } \\
\hline Benfica, FC Porto and Sporting & 33 & 2 & 31 & 6.1 \\
\hline Other teams from Primeira Liga & 20 & 20 & 0 & 100 \\
\hline \multicolumn{5}{|l|}{ La Gazzetta } \\
\hline Juventus, Inter, Milan, Napoli & 29 & 5 & 24 & 17.2 \\
\hline Other Serie A teams & 8 & 3 & 5 & 37.5 \\
\hline
\end{tabular}

As already mentioned, the four sports media outlets' level of accuracy in their coverage varied depending on the clubs and players involved. The research results, as Table 6 demonstrates, indicate that rumours about the top clubs published by all of them were generally less likely to be true than the ones about minor teams.

In this respect, the score obtained by Marca on both platforms was remarkably low $(n=3,21.4 \%)$. The rumours that it published about Real Madrid, FC Barcelona (the transfer of Rodrigo from Valencia and several candidates to replace Valverde as the new coach) and Atlético de Madrid (the transfer of Cavani from PSG) never proved to be true, except in three cases, while those about the rest of the teams in La Liga were ultimately confirmed in 11 out of 14 cases. Similarly, many of the rumours published by $A$ Bola were never substantiated (30.4\% on Twitter and $35.5 \%$ on its football homepage), although these were only about Benfica, Porto and Sporting.

Lastly, La Gazzetta's coverage included the highest proportion of rumours about top clubs that were ultimately confirmed $(53.1 \%$ on Twitter and $54.2 \%$ on its football homepage). For example, it initially published plenty of unverified news about the negotiations revolving around Christian Eriksen (Tottenham) and Ashley Young (Manchester United), with both players finally signing for Inter Milan, one of the most popular teams in the Serie A, which went a long way to boosting it score in this regard.

The four sports media outlets offered constant updates about likely transfers/loans between the major clubs in each league. Specifically, this included posting market updates and breaking news/rumours, sometimes by live blogging (Marca) and sometimes by publishing a summary of confirmed transfers in only one online piece at the end of the day ( $L a$ Gazzetta). Occasionally, minor teams made the headlines more frequently when one or more of their players were linked to top clubs. More often than not, deals involving minor clubs were covered once they had been officially announced by them. 
Table 6. The table shows rumours that finally happened or not regarding clubs involved.

\begin{tabular}{|c|c|c|c|c|}
\hline \multicolumn{5}{|l|}{ On Twitter } \\
\hline Media Outlet & Clubs & Rumours & Happened & Didn't \% \\
\hline \multicolumn{5}{|l|}{ Marca } \\
\hline R.Madrid/Barça/At. Madrid & 14 & 3 & 11 & 21.4 \\
\hline Other teams from La Liga & 14 & 11 & 3 & 78.6 \\
\hline \multicolumn{5}{|l|}{ Guardian Sport } \\
\hline Man Utd., Chelsea, Tottenham & 10 & 4 & 6 & 40 \\
\hline Other Premier League teams & 8 & 3 & 5 & 37.5 \\
\hline \multicolumn{5}{|l|}{ A Bola } \\
\hline Benfica, FC Porto, Sporting & 23 & 7 & 16 & 30.4 \\
\hline Other teams from Primeira Liga & 0 & 0 & 0 & - \\
\hline \multicolumn{5}{|l|}{ La Gazzetta } \\
\hline Juventus, Inter, Milan, Napoli & 32 & 17 & 15 & 53.1 \\
\hline Other Serie A teams & 11 & 2 & 9 & 18.2 \\
\hline \multicolumn{5}{|l|}{ On Websites } \\
\hline \multicolumn{5}{|l|}{ Marca } \\
\hline R.Madrid/Barça/At. Madrid & 14 & 3 & 11 & 21.4 \\
\hline Other teams from La Liga & 16 & 13 & 3 & 81.2 \\
\hline \multicolumn{5}{|l|}{ Guardian Sport } \\
\hline Man Utd., Chelsea, Tottemham & 15 & 5 & 10 & 33.3 \\
\hline Other Premier League teams & 8 & 6 & 2 & 75 \\
\hline \multicolumn{5}{|l|}{ A Bola } \\
\hline Benfica, FC Porto, Sporting & 31 & 11 & 20 & 35.5 \\
\hline Other teams from Primeira Liga & 0 & 0 & 0 & - \\
\hline \multicolumn{5}{|l|}{ La Gazzetta } \\
\hline Juventus, Inter, Milan, Napoli & 24 & 13 & 11 & 54.2 \\
\hline Other teams from Serie A & 5 & 3 & 2 & 60 \\
\hline
\end{tabular}

This was the case of Marca, which usually posted transfer news about minor clubs on Twitter, accompanied by a photograph of the player wearing the colours of his new club and an "official" tag to confirm that the transfer had happen. This outlet broadened its coverage of the 2020 winter transfer window on Twitter by using a specific account called @Marcatransfer. More news about minor clubs was posted on this handle than about their major counterparts (@Marca).

In light of the results, the European football transfer coverage of these four sports media outlets offered more analysis, opinions and statements on rumours about three or four major teams in each league than factual news about transfers/loans relating to them. Speculative content generally gained ground in their coverage of potential signings and negotiations between clubs.

\section{Discussion and Conclusions}

This research reflects how the combination of facts and rumours in football transfer coverage is widespread and may turn out to be misleading for audiences. This contravenes the traditional way of organising information to tell stories around fact-based evidence (Albright 2017) and the golden rules of objectivity and verification that have always applied to journalism (Kovach and Rosenstiel 2007; Owen Hearns-Branaman 2018). Mainstream sports media in fact play a significant role in the dissemination of non-factual stories (Tsfati et al. 2020), which challenges the normative standards of the profession contained in ethical codes, stylebooks and other accountability instruments aimed at covering sports responsibly (Wulfemeyer 1985; Ramon and Rojas-Torrijos 2018).

As with other kinds of news organisations, sports media outlets spread misinformation across their platforms through the use of declarative headlines in articles about unverified deals or negotiations in the football transfer window, as well as doing a poor job of 
clarifying, updating or correcting rumours covered by them when still unconfirmed as a way of closing the news loop for audiences (Silverman 2015).

Moreover, this consistent editorial line in mainstream sports media outlets, which prioritise football over any other professional sport in their day-to-day reporting (RojasTorrijos and Ramon 2021), usually results in a constrained and predictable news agenda that lacks diversity and is limited by the frequent uniformity of its stories (English 2018).

Notwithstanding the fact that the line between factual and non-factual news becomes blurred in most football transfer coverage, some efforts to improve practices may contribute to reduce the percentage of misinformation in sports reporting. Following the same editorial policy as BBC Sport (Stanton 2016), in two different sections The Guardian draws a clear distinction between gossip and news, thus allowing readers to tell the difference between confirmed facts and unverified rumours. In addition, to a lesser extent, Marca sometimes labels news indicating whether the piece is rumour or not.

On both their Twitter handles and their football homepages, the four national sports media outlets analysed in our study tended to publish more non-factual content about likely football deals than about sealed transfers or loans. The majority of those rumours about the 2020 winter transfer window included hidden content, a large quantity of unconfirmed news included content reframed with a false context which turned out to be misleading for readers, and, to a lesser extent, fabricated or manipulated content with factual inaccuracies mainly gleaned from unofficial or anonymous sources.

Although these sports media outlets published different types of inaccuracies, a high proportion of the reported rumours were ultimately confirmed by the clubs involved. These official confirmations actually increased the level of accuracy and/or reliability of their reporting.

Our findings also indicate that the proportion of rumours in the coverage of the 2020 winter transfer window normally varied in accordance with the relevance or popularity of the clubs and players featuring in the stories. In other words, the greater the coverage that was devoted to the three or four top teams and their most popular players in a national league, the more likely it was that those outlets would resort to speculative reporting.

In contrast, their coverage of the rest of the football clubs was more accurate, including much more factual content than hearsay. In addition, rumours about minor teams are more likely to happen than about major ones. Consequently, the level of accuracy of each of the four sports media outlets and the degree of misinformation in their coverage also varied depending on which club category the reporting was about in each country.

Misinformation about top clubs may reflect an effort by mainstream sports media outlets to attract the attention of their supporters and to engage them, maybe because they represent a relevant proportion of their readership. This relationship obliges them to deliver up-to-the-minute news about negotiations involving popular footballers from top teams, which ultimately makes reporting inaccuracies more probable. On the contrary, their coverage of other teams in national first divisions do not seem to be driven by such a necessity to publish constant updates. In this case, therefore, reporters have more time to verify whether or not a transfer has been really closed and, if so, to search for more details about it.

Given that football transfer window coverage is restricted to a few main players and bearing in mind the high level of misinformation about the top clubs, sports media outlets should strive to broaden their agendas, resort to more sources and deliver more confirmed news, in addition to official announcements. Furthermore, they should adopt more verification protocols in order to avoid factual inaccuracies, improve the quality of their newsgathering and enhance their trustworthiness and credibility.

To conclude, these results have significant implications for sports journalism in the current landscape, as they demonstrate the ways sports news outlets deliver football transfer unconfirmed rumours as sealed facts in a way to keep and attract audiences' attention and stand out in a context of a greater competitiveness between legacy and new media. Moreover, these findings suggest the sports journalism practice has been affected 
considerably by the rapid growth of social media, especially Twitter, where clickbait becomes a trend and complex stories and quality content are usually set aside in favour of gossips, controversies and non-factual pieces.

As with any study, this work has its limitations. Firstly, some parts of the misinformation matrix may require information about reporters' news-gathering that cannot be deciphered just from the published content analysed in this study. Secondly, to decipher misinformation in football transfer window is a very complex issue and our analysis turned to be somehow limited starting from our score system: Sometimes the reporting deal may be accurate according to news gathering methods but finally does not happen (maybe because of sources), or the transfer is reported at first instance as non-factual but even so might finally happen. This means that there should not be only considered as accurate the reporting deals that went through.

Thus, some groundwork is still needed for further research with a more qualitative approach and employing other methods, once taken into account the limitations of our study so far. So, we are planning participant observations in newsrooms and in-depth interviews with sports reporters and editors of the four sports media outlets in this study. Those future interviews would let us better analyse the procedures the sports journalists follow to verify the information and the number and quality of sources they handle before they publish a piece of news or a rumour about a transfer deal that has been done, was reported as sealed because negotiations actually happened but finally did not materialise, or if simply the information was built from a baseless (or fabricated) inaccurate rumour.

Secondly, this study only considered two platforms-Twitter and football homepages. Accordingly, further research is required to establish whether or not these findings can be extrapolated to other social networking sites, on which news outlets also attempt to reach and engage their audiences.

Finally, it only analysed four media outlets from different countries. Although they are all analytically relevant, future research should have a broader scope, perhaps by including sports media outlets from other countries with important national football leagues, such as France (Ligue 1) and Germany (Bundesliga) in Europe and Brazil (Brasileirão) and Argentina (Primera División) in South America.

Last but not least, the study that we have described here was performed on the last transfer window before the COVID-19 pandemic. So, future research could address its impact on the coverage of the football transfer market.

Since the way in which misinformation makes its way into football coverage is still an underexplored issue, one of the objectives of our study has been to lay the groundwork for future research aimed at performing a more comprehensive and in-depth analysis on this phenomenon.

Author Contributions: Conceptualization, J.L.R.T. and M.S.M.; methodology, J.L.R.T.; software, J.L.R.T. and M.S.M.; validation, J.L.R.T. and M.S.M.; formal analysis, J.L.R.T. and M.S.M.; investigation, J.L.R.T. and M.S.M.; resources, J.L.R.T. and M.S.M.; data curation, J.L.R.T. and M.S.M.; writingoriginal draft preparation, J.L.R.T. and M.S.M.; writing—review and editing, J.L.R.T. and M.S.M.; visualization, J.L.R.T.; supervision, J.L.R.T.; project administration, J.L.R.T. All authors have read and agreed to the published version of the manuscript.

Funding: This research received no external funding.

Institutional Review Board Statement: Not applicable.

Informed Consent Statement: Not applicable.

Data Availability Statement: Not applicable.

Conflicts of Interest: The authors declare no conflict of interest. 


\section{References}

AIMC. 2021. Estudio General de Medios. Ranking Tipología de Soportes Internet [General Media Study. Internet Platform Type Ranking]. Available online: http:/ / reporting.aimc.es/index.html\#/main/internet (accessed on 20 July 2021).

Albright, Jonathan. 2017. Welcome to the Era of Fake News. Media and Communication 5: 87-89. [CrossRef]

Allen, Jennifer, Baird Howland, Markus Mobius, David Rothschild, and Duncan J. Watts. 2020. Evaluating the Fake News Problem at the Scale of the Information Ecosystem. Science Advances 6: eaay3539. Available online: https://www.science.org/doi/pdf/10.1 126/sciadv.aay3539 (accessed on 5 October 2021). [CrossRef] [PubMed]

Boyle, Raymond. 2006. Sports Journalism: Context and Issues. London: Sage, ISBN 9781412907989.

Bradshaw, Tom. 2021. Benefit or burden? Social media and moral complexities confronting sports journalists. In Insights on Reporting Sports in the Digital Age. Edited by Roger Domeneghetti. London: Routledge, pp. 17-30. ISBN 9780367819477.

Brunner, Steffan, and Thomas Horky. 2017. La prensa deportiva, una tipología periodística bajo presión [Sports Journalism in Print-A Media Genre under Pressure]. In Periodismo Deportivo de Manual. Edited by José Luis Rojas-Torrijos. Valencia: Tirant Humanidades, pp. 31-58. ISBN 9788416786572.

Cable, Jonathan, and Glyn Mottershead. 2018. “Can I click it? Yes you can": Football journalism, Twitter and clickbait. International Journal of Communication Ethics 15: 69-80. Available online: https://core.ac.uk/download/pdf/153533968.pdf (accessed on 5 October 2021).

Chadwick, Simon. 2013. The Science behind Football Transfer Rumours. The Conversation, July 24. Available online: https:// theconversation.com/the-science-behind-football-transfer-rumours-16293 (accessed on 20 July 2021).

Crolley, Liz, and David Hand. 2002. Football, Europe, and the Press. London: Frank Cass, ISBN 9780714680170.

Domeneghetti, Roger. 2021. Insights on Reporting Sports in the Digital Age. London: Routledge, ISBN 9780367819477.

Ekström, Mats, and Seth C. Lewis. 2020. Epistemologies of digital journalism and the study of misinformation. New Media $\mathcal{E}$ Society 22: 205-12. [CrossRef]

English, Peter. 2016. Twitter's diffusion in sports journalism: Role models, laggards and followers of the social media innovation. New Media E Society 18: 484-501. [CrossRef]

English, Peter. 2018. Sports Journalism. In Oxford Research Encyclopedia of Communication. Edited by Jon Nussbaum. Oxford: Oxford University Press, pp. 1-18. ISBN 9780190228613.

Hayes, Arthur, Jane Singer, and Jerry Ceppos. 2007. Shifting Roles, Enduring Values: The Credible Journalist in a Digital Age. Journal of Mass Media Ethics 22: 262-79. [CrossRef]

Ireton, Cherilyn, and Julie Posetti. 2018. Journalism, 'Fake News' and Disinformation. Paris: UNESCO, ISBN 9789231002816.

Kapferer, Jean-Nöel. 2013. Rumors: Uses, Interpretation and Necessity. New Brunswick: Transaction Publishers, ISBN 9781351492485.

Kovach, Bill, and Tom Rosenstiel. 2007. The Elements of Journalism: What Newspeople Should Know and the Public Should Expect. New York: Three Rivers Press, ISBN 9780307346704.

Krippendorf, Klaus. 2019. Content Analysis. An Introduction to Its Methodology, 4th ed. London: Sage, ISBN 9781412983150.

Moritz, Brian, and Michael Mirer. 2021. The end of the scoop scoreboard. Boundary work and breaking news in sports journalism. In Insights on Reporting Sports in the Digital Age. Edited by Roger Domeneghetti. London: Routledge, pp. 138-54. ISBN 9780367819477.

Murray, Bill. 1998. The World's Game. A History of Soccer. Chicago: University of Illinois Press, ISBN 9780252017483.

Nielsen, Rasmus Kleis, and Lucas Graves. 2017. News You Don't Believe: Audience Perspectives on Fake news. Reuters Institute for the Study of Journalism. Available online: https:/ / reutersinstitute.politics.ox.ac.uk/our-research/news-you-dont-believeaudience-perspectives-fake-news (accessed on 20 July 2021).

Owen Hearns-Branaman, Jesse. 2018. Journalism and the Philosophy of Truth: Beyond Objectivity and Balance. London: Routledge, ISBN 9781138599581.

Plaisance, Patrick Lee. 2013. Media Ethics. Key Principles for Responsible Practice, 2nd ed. Thousand Oaks: Sage, ISBN 9781452258089.

Ramon, Xavier, and José Luis Rojas-Torrijos. 2017. Mapping media accountability instruments in sports journalism. El Profesional de la Información 26: 159-71. [CrossRef]

Ramon, Xavier, and José Luis Rojas-Torrijos. 2018. Accountable sports journalism. Building up a platform and a new specialised code in the field. International Journal of Communication Ethics 15: 15-28.

Reilly, Thomas, and Mark Williams. 2003. Science and Soccer, 2nd ed. London: Routledge, ISBN 9780415262323.

Rojas-Torrijos, José Luis, and Xavier Ramon. 2021. Exploring Agenda Diversity in European Public Service Media Sports Desks: A Comparative Study of Underrepresented Disciplines, Sportswomen and Disabled Athletes' Coverage on Twitter. Journalism Studies 22: 225-42. [CrossRef]

Rojas-Torrijos, José Luis. 2012. La futbolización de la información deportiva. Un estudio de casos de cuatro diarios deportivos europeos. Revista Comunicação \& Cultura 13: 77-95. [CrossRef]

Rojas-Torrijos, José Luis. 2018. La estrategia digital de internacionalización de Marca en Latinoamérica. Estudio de caso de MARCA Claro en México. Revista de Comunicación 17: 133-54. [CrossRef]

Rosenberg, Howard, and Charles S. Feldman. 2008. No Time to Think; The Menace of Media Speed and the 24-Hour News Cycle. New York: The Continuum International Publishing Group, ISBN 9780826429315.

Schultz, Brad, and Mary Lou Sheffer. 2010. An Exploratory Study of How Twitter Is Affecting Sports Journalism. International Journal of Sport Communication 3: 226-39. [CrossRef] 
Sherwood, Merryn, Angela Osborne, Matthew Nicholson, and Emma Sherry. 2017. Newswork, news values, and audience considerations: Factors that facilitate media coverage of women's sports. Communication E Sport 5: 647-68. [CrossRef]

Silverman, Craig. 2015. Lies, Damn Lies, and Viral Content: Examining the Role of News Websites. New York: Tow Center for Digital Journalism. Available online: https:/ / academiccommons.columbia.edu/doi/10.7916/D8Q81RHH (accessed on 20 July 2021).

Smith, Rory. 2017. The Original Fake News: Soccer Transfers. The New York Times, July 13. Available online: https:/ / www.nytimes. $\mathrm{com} / 2017 / 07 / 13 /$ sports / soccer/premier-league-transfers-window.html (accessed on 20 July 2021).

Stanton, John. 2016. January transfer window: Can you believe gossip column rumours? BBC Sport, December 29. Available online: https:/ / www.bbc.com/sport/football/37975118 (accessed on 20 July 2021).

Tandoc, Jr., Edson C., Zheng Wei Lim, and Richard Ling. 2018. Defining 'Fake News'. Digital Journalism 6: 137-53. [CrossRef]

Thorson, Emily. 2016. Belief echoes: The persistent effects of corrected misinformation. Political Communication 33: 460-80. [CrossRef]

Torrebadella, Xavier, and Javier Olivera. 2013. The Birth of the Sports Press in Spain Within the Regenerationist Context of the Late Nineteenth Century. The International Journal of the History of Sport 30: 2164-96. [CrossRef]

Tsfati, Yariv, Hajo G. Boomgaarden, Jesper Strömbäck, Rens Vliegenthart, Alyt Damstra, and Elina Lindgren. 2020. Causes and consequences of mainstream media dissemination of fake news: Literature review and synthesis. Annals of the International Communication Association 44: 157-73. [CrossRef]

Vosoughi, Soroush, Deb Roy, and Sinan Aral. 2018. The spread of true and false news online. Science 359: 1146-51. [CrossRef] [PubMed]

Waisbord, Silvio. 2018. Truth is What Happens to News: On Journalism, Fake News, and Post-Truth. Journalism Studies 19: 1866-78. [CrossRef]

Wardle, Claire. 2019. First Draft's Essential Guide to Understanding Information Disorder. Cambridge: First Draft News. Available online: https:/ / firstdraftnews.org/wp-content/uploads/2019/10/Information_Disorder_Digital_AW.pdf?x76701 (accessed on 20 July 2021).

Webster, James G. 2014. The Marketplace of Attention: How Audiences Take Shape in a Digital Age. Cambridge: The MIT Press, ISBN 9780262027861.

Wulfemeyer, K. Tim. 1985. Ethics in sports journalism: Tightening up the code. Journal of Mass Media Ethics 1: 57-67. [CrossRef] 